\title{
Effect of sub-MIC concentrations of metronidazole, vancomycin, clindamycin and linezolid on toxin gene transcription and production in Clostridium difficile
}

\author{
Correspondence \\ Michael Gerber \\ michael.gerber@medizin. \\ uni-leipzig.de
}

Received 31 October 2007

Accepted 11 February 2008

\author{
Michael Gerber,${ }^{1} \dagger$ Christiane Walch, ${ }^{1}$ Birgit Löffler, ${ }^{1} \ddagger$ Kristin Tischendorf, ${ }^{1}$ \\ Udo Reischl ${ }^{2}$ and Grit Ackermann ${ }^{1} \dagger$
}
${ }^{1}$ Institute of Medical Microbiology and Epidemiology of Infectious Diseases, University of Leipzig, Liebigstraße 24, 04103 Leipzig, Germany
${ }^{2}$ Institute of Medical Microbiology and Hygiene, University Hospital of Regensburg, Franz-Josef- Strauss-Allee 11, 93053 Regensburg, Germany

\begin{abstract}
Clostridium difficile is the major cause of hospital-acquired infectious diarrhoea. Several antimicrobials are known to induce and promote $C$. difficile-associated diarrhoea (CDAD). The impact of metronidazole (MTR), vancomycin (VAN), clindamycin (CLI) and linezolid (LZD) on growth, toxin gene transcription and toxin production in C. difficile was investigated. Four C. difficile strains were grown with and without sub-MIC concentrations of MTR, VAN, CLI and LZD $(0.5 \times \mathrm{MIC})$ and growth was measured by colony counts. Toxin production was detected using ELISA (for toxin A) and a cytotoxicity assay (for toxin B) in culture supernatants and also in sonicated cells. Real-time PCR was used to measure transcription of the toxin $A$ and $B$ genes. The aim of this work was to combine analysis of toxin A and B production by ELISA or cell culture assay with transcriptomic analysis. The four strains showed similar growth and different levels of toxin production in the absence of antibiotics. An antibiotic-free control showed toxin production at a late stage when the plateau phase of bacterial growth was reached, whereas antibioticexposed strains showed earlier toxin production. All of the antibiotics used except CLI increased the transcription rate of toxin genes. The findings of this study show that sub-MIC concentrations of antibiotics can cause changes in gene transcription of the major virulence factors of $C$. difficile. This study describes a new method for transcriptomic analysis of toxin genes in C. difficile.
\end{abstract}

\section{INTRODUCTION}

Clostridium difficile is a Gram-positive, spore-forming, obligately anaerobic rod-shaped bacterium. After its first isolation in 1935 (Hall \& O'Toole, 1935), the role of $C$. difficile as an important cause of antibiotic-associated diarrhoea remained undiscovered for a long time. Fortythree years later, in 1978, a correlation between C. difficileassociated diarrhoea (CDAD), pseudomembranous colitis (PMC) and antibiotics was established (Bartlett et al., 1978; Larson et al., 1978). The clinical appearance of C. difficile infection ranges from asymptomatic to mild self-limiting diarrhoea to severe diarrhoea with possible complications such as perforation, ileus and toxic megacolon. Nearly all

tPresent address: Institute of Clinical Chemistry and Molecular Diagnostics, University Hospital Leipzig, Paul-List-Straße 13-15, 04103 Leipzig, Germany.

¥Present address: Department for Molecular Cell Therapy, University of Leipzig, Deutscher Platz 5, 04103 Leipzig, Germany.

Abbreviations: CDAD, Clostridium difficile-associated diarrhoea; CLI, clindamycin; LZD, linezolid; MTR, metronidazole; PMC, pseudomembranous colitis; VAN, vancomycin. antibiotics are thought to be able to initiate $C$. difficile infection, but broad-spectrum agents such as cephalosporins, clindamycin and, as described recently, fluoroquinolones are the agents most frequently reported to be associated with CDAD and PMC (Dodson \& Borriello, 1996; Jones et al., 1997; Kelly et al., 1994; Pepin et al., 2005). The pathogenesis is known to start with the colonization of the gut with $C$. difficile after the resident bacterial microbiota has been eliminated by antibiotics. The overgrowth of virulent strains of $C$. difficile results in the production of their major virulence factors: toxin $\mathrm{A}$ and toxin B (Farrell \& LaMont, 2000). With molecular masses of 308 and $207 \mathrm{kDa}$, respectively, these toxins are the largest bacterial toxins known and express potent cytotoxicity and enterotoxicity (Dove et al., 1990). Toxin production is affected by a large number of factors, such as temperature, biotin limitation, amino acid concentration, glucose concentration and alteration of the oxidationreduction potential (Barc et al., 1992; Dupuy \& Sonenshein, 1998; Honda et al., 1983; Ikeda et al., 1998; Karlsson et al., 1999; Onderdonk et al., 1979). An interesting effect on the production of toxin was described 
by Onderdonk et al. (1979), whereby subinhibitory concentrations of vancomycin (VAN) and penicillin increased toxin production during continuous culture. It was supposed that the marked elevation of toxin titres in supernatant fluids was caused by a net efflux from the intracellular to the extracellular compartments induced by cell-wall-active antibiotics, although the mechanism of toxin increase remained unclear. Several years later, a toxin-inducing effect in $C$. difficile was recognized for clindamycin (CLI) and cephalosporins (Honda et al., 1983). Recently, many studies have provided information about the physiological effects of sub-MIC antibiotic concentrations in different species (Davies et al., 2006). The described changes induced by different antibiotics are highly diverse. Several studies on pharmacodynamic effects in $C$. difficile including sub-MIC concentrations have been published (Drummond et al., 2003; Odenholt et al., 2007). However, none has investigated the association of antimicrobials and toxin production with mRNA levels.

The aim of this study was to determine the effect of subMIC concentrations of antibiotics on the growth and toxin production of four strains of $C$. difficile. Four antibiotics were investigated, comprising agents that are used for the treatment of CDAD [VAN and metronidazole (MTR)], predispose for it (CLI) or have recently been discussed as a treatment possibility [linezolid (LZD)]. The study included experiments to differentiate between toxin levels in supernatant and sonicated cells. The increased toxin levels noted could reflect either a release of preformed toxin from the bacterial cell or synthesis of additional toxin. Previous studies that also aimed to differentiate between toxin levels in supernatants and sonicated cells have discussed enhanced production or release of toxin (Nakamura et al., 1982; Onderdonk et al., 1979). Here, a new method of quantitative real-time PCR using LightCycler technology was developed to determine the levels of gene transcription of the toxin $\mathrm{A}$ and $\mathrm{B}$ genes, $t c d A$ and $t c d B$, in $C$. difficile.

\section{METHODS}

Strains of C. difficile. Four strains of $C$. difficile were used in this study: VPI 10463 (ATCC 43255), strain 2932 (a local endemic strain, toxinotype VIII, that was isolated at University Hospital Leipzig, Germany, which has a deletion in the pathogenicity locus and is unable to produce toxin A), strain 47 and strain 317 (both local endemic strains that were isolated at Bonn University Hospital, Germany). Strains VPI 10463, 47 and 317 all belong to toxinotype 0. Strains 2932 and 47 were positive for the ermB gene and showed $\mathrm{MLS}_{\mathrm{B}}$ resistance. All strains were tested four times for their susceptibility to the four antibiotics investigated in this study using the Etest on Columbia agar. PCR of the $t c d A$ and $t c d B$ sequences was positive for all strains, but strain 2932 produced a shortened $1.3 \mathrm{~kb}$ A1 fragment due to the deletion in the pathogenicity locus. All strains were stored at $-80{ }^{\circ} \mathrm{C}$.

Antimicrobials. Antibiotic powders used in this study were VAN, MTR, CLI (all from Sigma) and LZD (Pfizer). Antibiotics were stored according to the manufacturer's instructions and prepared fresh daily in sterile distilled water as a $10 \times$ solution with reference to the highest concentration required.

Growth curves. Strains were grown on pre-reduced cycloserine/ cefoxitin/fructose agar (Oxoid) in an anaerobic chamber (Heraeus Instruments) for $48 \mathrm{~h}$ (George et al., 1979). Anaerobic conditions provided by the anaerobic chamber were $80 \% \mathrm{~N}_{2}, 15 \% \mathrm{CO}_{2}$ and $5 \%$ $\mathrm{H}_{2}$ at $37^{\circ} \mathrm{C}$. After incubation and a purity check on pre-reduced Columbia agar (Oxoid) for another $48 \mathrm{~h}$, one colony was inoculated in $5 \mathrm{ml}$ pre-reduced brain heart infusion (BHI) broth (Oxoid) for $24 \mathrm{~h}$. Ten microlitres was then added to another $5 \mathrm{ml}$ pre-reduced BHI broth and incubated for $12 \mathrm{~h}$.

Bacterial density was related to McFarland standards (McFarland $1=3 \times 10^{8}$ c.f.u. $\mathrm{ml}^{-1}$; bioMérieux). By measuring $\mathrm{OD}_{550}$, an inoculum of $3 \times 10^{6}$ cells $\mathrm{ml}^{-1}$ was incubated in $250 \mathrm{ml} \mathrm{BHI}$ containing the appropriate antibiotic concentration $(0.5 \times \mathrm{MIC})$. An antibiotic-free control was used for each strain. All actions were performed under anaerobic conditions in an anaerobic chamber. All growth media were pre-reduced.

Bacterial growth was measured by counting plated cells at $0,4,8,12$, 16, 20 and $24 \mathrm{~h}$. At each time point, serial 10 -fold dilutions of the culture were plated on pre-reduced Columbia agar and incubated for $48 \mathrm{~h}$. For each time point, samples were taken as follows: (i) $1 \mathrm{ml}$ for subsequent toxin A ELISA; (ii) $1 \mathrm{ml}$ for subsequent detection of toxin B in cell culture; and (iii) $25 \mathrm{ml}$ for RNA extraction. Samples (i) and (ii) were centrifuged for $5 \mathrm{~min}$ at $6000 \mathrm{~g}$ and the supernatants were filtered $(0.22 \mu \mathrm{m}$; Sartorius $)$ and transferred to new $1.5 \mathrm{ml}$ tubes. The remaining pellets were sonicated three times (Vibra-Cell; Sonics \& Materials) for $2 \mathrm{~min}$, centrifuged for $4 \mathrm{~min}$ at $5300 \mathrm{~g}$, filtered and transferred to new $1.5 \mathrm{ml}$ tubes. Both supernatants and sonicated pellets were stored at $-80{ }^{\circ} \mathrm{C}$ until toxin analysis. Sample (iii) was centrifuged for $5 \mathrm{~min}$ at $5300 \mathrm{~g}$. The supernatant was discarded and the approximately $200 \mu \mathrm{l}$ pellet was retrieved. The RNA was stabilized by the addition of $400 \mu$ l RNAprotect Bacteria Reagent (Qiagen) and stored at $-80{ }^{\circ} \mathrm{C}$ until extraction. Samples were not stored longer than 1 week. All growth curves were performed in triplicate.

Toxin A ELISA. Levels of toxin A were measured by ELISA in supernatants as well as in sonicated cells using the ProSpecT 2 kit (Alexon-Trend) according to the manufacturer's instructions. Cells of each sample were sonicated three times for 2 min each using a VibraCell. Two hundred microlitres of each sample was used in the assay. Reading of the microtitre plates was performed at a wavelength of $450 \mathrm{~nm}$. An $A_{450}$ reading above $0.1-3$ was considered positive. No further dilutions of pellet and supernatant were made when $A_{450}$ was above 3 .

Toxin B cell culture. Toxin B titres from culture supernatants and from sonicated cells were measured using a cytotoxicity assay. An African green monkey kidney (Vero) cell line was used and suspended in Dulbecco's modified Eagle's medium (DMEM) containing $1 \%$ fetal calf serum (FCS; Seromed-Biochrom KG) and $2 \mu$ gentamicin (Ratiopharm) $\mathrm{ml}^{-1}$. The FCS was free of $C$. difficile toxin $\mathrm{B}$ antibodies. A negative control of gentamicin-free DMEM showed no cytopathic effect. Cell density was measured microscopically in a counting chamber (Feinoptik) and $2 \times 10^{4}$ cells were added to each well of a 96-well plate (Greiner). The cells were incubated for $24 \mathrm{~h}$ at $37^{\circ} \mathrm{C}$ to achieve a homogeneous monolayer. One hundred microlitres of supernatant or sonicated cells diluted in DMEM was added to the Vero cell monolayers at dilutions ranging from $1: 3$ to $1: 6561$. After $48 \mathrm{~h}$, the cytotoxic effect was documented using an inverted microscope equipped with a camera. The last dilution resulting in cytopathic effect was reported as the titre. All cytotoxicity tests were performed in duplicate. 
Extraction of RNA. Two volumes of RNAprotect Bacteria Reagent (Qiagen) were added to the bacterial pellet to stabilize the bacterial mRNA. Because there is no stable expression of housekeeping genes in C. difficile, an internal standard was used to control RNA loss during the extraction process and to enable an accurate quantification of mRNA levels. The standard was of a similar length to the target sequence and contained the same primer binding sequence. Binding of hybridization probes by the RNA standard was different due to specifically introduced sequences. Thus measuring both standard and original target sequences in one tube after exposure to RNA extraction, reverse transcription and amplification was possible. Bacterial RNA was prepared using peqGOLD RNA Pure (peqLab) according to the manufacturer's instructions. Three samples were extracted for each condition. RNA concentration and purity were determined by measuring $A_{260 / 280}$.

After extraction, a DNase I (RQ1 RNase-Free DNase; Promega) treatment step was performed using $1 \mathrm{U}$ DNase $(\mu \mathrm{g} \text { RNA) })^{-1}$ at $37^{\circ} \mathrm{C}$ for $30 \mathrm{~min}$. RQ1 DNase Stop Solution (Promega) was used to terminate the reaction and the DNase was inactivated by incubation at $65{ }^{\circ} \mathrm{C}$ for $10 \mathrm{~min}$.

Reverse transcription. LightCycler RT-PCR was performed using a Qiagen OneStep RT-PCR kit. Specific primers and two different reverse transcriptases (Omniscript and Sensiscript) were used. Each transcriptase is highly specific for a certain length of template mRNA.

For cDNA synthesis, $4 \mu \mathrm{l}$ RNA was added to $20 \mu \mathrm{l}$ RT master mix, which contained each specific primer at a concentration of $1.2 \mu \mathrm{M}$, $400 \mu \mathrm{M}$ dNTPs, $0.8 \mu$ l Qiagen OneStep RT-PCR enzyme mix and $8 \mathrm{U}$ RNasin (Promega) per reaction. The incubation time was $30 \mathrm{~min}$ at $50{ }^{\circ} \mathrm{C}$. The initial PCR activation and also inactivation of the reverse transcriptases were performed at $95{ }^{\circ} \mathrm{C}$ for $15 \mathrm{~min}$.

LightCycler RT-PCR. A primer pair was used to amplify a segment within the $C$. difficile $t c d A 1$ gene (411 bp) and a second primer pair was chosen to amplify a segment within the $C$. difficile $t c d B 2$ gene (403 bp) (Table 1). Specific hybridization probes (Table 2) labelled with LightCycler Red (LC Red) and fluorescein were designed. Synthesis of probes was carried out at Tib-MolBiol (Berlin, Germany). The master mix used for amplification and hybridization of probe based on detection of the $t c d A 1$ - and $t c d B 2$-specific amplicons was as follows: $375 \mathrm{nM}$ each primer, $150 \mathrm{nM}$ each hybridization probe, $250 \mu \mathrm{M}$ each dNTP, $1 \mathrm{U}$ Platinum Taq DNA polymerase (Invitrogen), $10 \mathrm{ng}$ BSA (Sigma) $\mu \mathrm{l}^{-1}, 2 \mu \mathrm{l}$ corresponding template RNA, and $5 \mathrm{mM} \mathrm{MgCl}_{2}$ for the $t c d A 1$ PCR and $3.75 \mathrm{mM}$ $\mathrm{MgCl}_{2}$ for the $t c d B 2$ PCR. Negative and positive controls were included in all experiments. The negative control sample was prepared by replacing the DNA template with PCR-grade water. The positive control sample was prepared by adding $2 \mu \mathrm{l} C$. difficile RNA standard to the master mix. The following PCR profile was used for amplification and hybridization probe-based detection of the $t c d A 1$ - and $t c d B 2$-specific amplicons: initial denaturation for $2 \mathrm{~min}$ at $95{ }^{\circ} \mathrm{C}$; amplification for 50 cycles of $10 \mathrm{~s}$ at $95{ }^{\circ} \mathrm{C}, 10 \mathrm{~s}$ at $50{ }^{\circ} \mathrm{C}$ and $20 \mathrm{~s}$ at $72{ }^{\circ} \mathrm{C}$ (temperature transition rate: $20{ }^{\circ} \mathrm{C} \mathrm{s}^{-1}$; acquisition mode: single); followed by cooling for $2 \mathrm{~min}$ at $40{ }^{\circ} \mathrm{C}$. Readout of LC
Red 640 values was performed in channel F2 and readout of LC Red 705 values in channel F3.

\section{RESULTS AND DISCUSSION}

The MICs of the four antibiotics for each strain are shown in Table 3. Bacterial growth was assessed by counting colonies to determine the number of c.f.u. Fig. 1 shows growth curves for all four strains with and without the antibiotics. Variations in growth patterns among the four strains in the untreated control were small. After $4 \mathrm{~h}$, each strain reached the exponential phase and after $12 \mathrm{~h}$ they reached the stationary phase. Under the influence of antibiotics, the stationary phase was reached later, confirming the results of an earlier study (Drummond et al., 2003). In antibiotic-free medium, toxin production in all four strains started at the same time. After $16 \mathrm{~h}$, toxin $\mathrm{B}$ was found in the supernatant, whereas toxin A was detectable after $20 \mathrm{~h}$. Generally, toxin B was detectable $4 \mathrm{~h}$ earlier than toxin $\mathrm{A}$, and toxins were detectable $4 \mathrm{~h}$ earlier in sonicated cells than in supernatant. The levels of toxins measured by ELISA and cytotoxicity assay in supernatant and pellet for strain VPI 10463 are shown in Table 4 . However, the amount of toxin produced was different among the strains. Strain VPI 10463 and 317 (titre of $1: 6561$ after $24 \mathrm{~h}$ ) produced more toxin $\mathrm{B}$ than strains 2932 and 47 (titre of $1: 2187$ after $24 \mathrm{~h}$ ) in supernatant and pellet. After $24 \mathrm{~h}$, all strains except strain 2932 produced toxin A that exceeded the measurable level of the assay ( $A_{450}$ of 3.0).

Under the influence of subinhibitory concentrations of antibiotics, variations in growth, toxin production and transcriptomic activity among the strains were observed. Subinhibitory concentrations of antibiotics seemed to delay bacterial growth and increased the time until the stationary phase was reached. Comparing the antibiotic-treated strains with the untreated control, toxin detection was possible up to $12 \mathrm{~h}$ earlier (Table 4).

During bacterial growth $(4-16 \mathrm{~h})$, toxin $\mathrm{A}$ and $\mathrm{B}$ production is supposed to be down-regulated due to the expression of $t c d C$ or, as recently described, $c o d Y$ (Dineen et al., 2007; Hundsberger et al., 1997). The results of this study showed increased toxin $\mathrm{A}$ and $\mathrm{B}$ detection during the exponential phase for those strains exposed to sub-MIC VAN, MTR and LZD (Table 4). This effect was not noticed for CLI. In the stationary growth phase (20-24 h), toxin production reached and stayed at the same level as in the

Table 1. Primer sequences for amplification of $C$. difficile $t c d A 1$ and $t c d B 2$ sequences

\begin{tabular}{|lllcl|}
\hline Gene & Primer & \multicolumn{1}{c|}{ Sequence $\left(\mathbf{5}^{\prime} \rightarrow \mathbf{3}^{\prime}\right)$} & Position $(\mathbf{n t})$ & Length \\
\hline$t c d A 1$ & A1F & GAGAAGTCAGTGATATTGCTCTTGA & $12616-12640$ & $411 \mathrm{bp}$ \\
& A1R & CCCTGATATCTATCCCATGATTACT & $13026-13002$ & \\
\multirow{2}{*}{$\mathrm{t} d \mathrm{~B} 2$} & YT100 & GTGCAGCAATCAAAGAGCTAAGTG & $6980-7003$ & $404 \mathrm{bp}$ \\
& YT101 & TGAACCACCTTCCATTCTCCAG & $7383-7362$ & \\
\hline
\end{tabular}


Table 2. Hybridization probe sequences

\begin{tabular}{|lll|}
\hline Probe & Target gene & \multicolumn{1}{c|}{ Sequence $\left(\mathbf{5}^{\prime} \rightarrow \mathbf{3}^{\prime}\right)^{\star}$} \\
\hline HP A1-3 & A1 & AGGCTATAGTTGAATCTTCTACCACT-FL \\
HP A1-4 & & LC Red 640-AAGCATTACAGCTACTAGAGGAAGAGATT-PH \\
HP B2-3 & B2 & AAGGAGTATTTACTTTATTAGATGATAA-FL \\
HP B2-4 & & LC Red 640-ATAATGATGCCACAAGATGATTTAG-PH \\
HP-BpaF & RNA standard & GTTCTACCAAAGACCTGCCTGGGC-FL \\
HP Bpa & & LC Red 705-AGACAAGCCTGGAACCACTGGTAC-PH \\
\end{tabular}

${ }^{*}$ LC Red, LightCycler Red; FL, fluorescein; PH, phosphate.

controls without antibiotics. The results of toxin mRNA quantification were similar (Fig. 2).

To compare mRNA levels under different growth conditions, the number of mRNA copies was divided by the number of c.f.u. $\mathrm{ml}^{-1}$ (i.e. mRNA per cell). During the exponential phase of bacterial growth, the transcription ratio was increased up to $10^{6}$-fold under the influence of VAN, MTR and LZD, whereas the level of mRNA per cell in the untreated control remained below the level in the antibiotic-treated strains (Fig. 2). In the stationary phase, the transcription activity of antibiotic-treated strains was reduced. However, the antibiotic-free control showed high numbers of mRNA per cell. Again, results for CLI were different (no increase in mRNA per cell) from those for the other antibiotics used.

It is obvious that there is a strong association between use of antibiotics, C. difficile infection, CDAD and PMC. A prerequisite for $C$. difficile infection, the depletion of the normal protective bowel flora, is caused by broad-spectrum antibiotics. Once the balance of the gut is disturbed, opportunistic micro-organisms can cause an infection via the now-available binding sites and the excess of nutrients. The use of antibiotics leads to suppression of colonization resistance and promotes the development and progress of C. difficile infection, CDAD and PMC (Farrell \& LaMont, 2000). Consequently, $C$. difficile is the major cause of hospital-acquired infectious diarrhoea.

In the last several years, studies have been published on antibiotics inducing CDAD not only by alteration of commensal gut flora but also by influencing pathogenicity via physiological effects (Drummond et al., 2003). Over 20 years ago, the first reports suggested that certain antibiotics increased the production of the two $C$. difficile toxins

Table 3. MICs of the four antibiotics ( $\mathrm{mg} \mathrm{l}^{-1}$ )

\begin{tabular}{|llccc|}
\hline MIC & VPI 10463 & Strain 2932 & Strain 47 & Strain 317 \\
\hline VAN & 0.5 & 1 & 2 & 1 \\
MTR & 0.0175 & 0.06 & 0.75 & 0.25 \\
LZD & 0.75 & 16 & 1.5 & 1.5 \\
CLI & 4 & $>256$ & $>256$ & 4 \\
\hline
\end{tabular}

(Honda et al., 1983; Onderdonk et al., 1979). As with C. difficile, antibiotics are considered to have an effect on the expression of virulence factors in other species, including Escherichia coli, Vibrio cholerae, meticillin-sensitive Staphylococcus aureus and meticillin-resistant S. aureus (Levner et al., 1977; Ohlsen et al., 1998; Yoh et al., 1983). It is evident that concentrations of antibiotic lower than those required for inhibition induce multiple effects in almost all bacterial species (Davies et al., 2006).

As shown in Table 4 and Fig. 2, toxin production was initiated earlier with subinhibitory concentrations of antibiotics than in antibiotic-free medium. Even at subinhibitory concentrations, antibiotics seem to cause stress to bacteria. The stress response includes activation of several genes that are thought to affect toxin promoters. A recent study showed that UviA, a UV-inducible regulator from Clostridium botulinum, was induced by treatment with UV light or mitomycin $\mathrm{C}$ after the cell experienced DNA damage. UviA is related to a special class of $\sigma$ factors found in Clostridium species, responsible for activating transcription of toxin genes (Dupuy et al., 2005). Temperature also seems to be a factor influencing toxin production (Karlsson et al., 2003). Another study showed that antibiotics increase the levels of GroEL, a protein that works as a surface adhesin and helps $C$. difficile colonize recently vacated binding sites left by depleted normal bacterial flora (Hennequin et al., 2003). These findings suggest that, under adverse conditions such as the presence of antibiotics, increased expression levels of certain genes may help $C$. difficile to survive.

Four different antibiotics with distinct modes of action were investigated. VAN as a glycopeptide inhibits a late stage in bacterial cell wall peptidoglycan synthesis; MTR inhibits nucleic acid synthesis and leads to cell death. The oxazolidinone LZD inhibits protein synthesis by binding at the $\mathrm{P}$ site of the ribosomal $50 \mathrm{~S}$ subunit. No studies have investigated the sub-MIC effects of LZD in C. difficile before. As a member of the lincosamide group, CLI inhibits bacterial protein synthesis and acts specifically on the $50 \mathrm{~S}$ subunit of the bacterial ribosome. Application of usual doses results in bacteriostatic activity. Higher concentrations, as reached in vitro, may even be bactericidal (Spizek \& Rezanka, 2004). CLI affects protein synthesis by blocking the ribosome. 

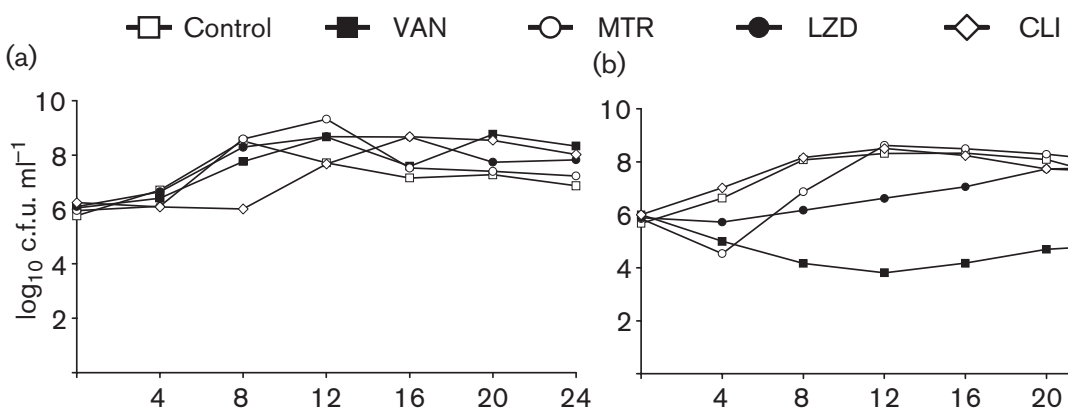

(b)

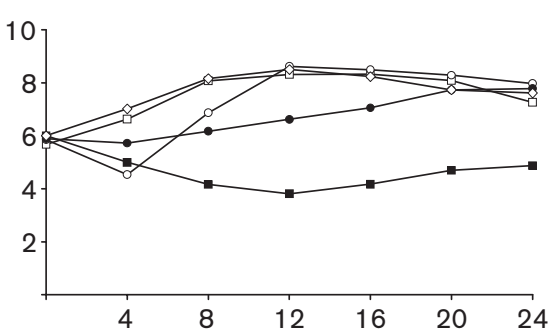

(c)

(d)
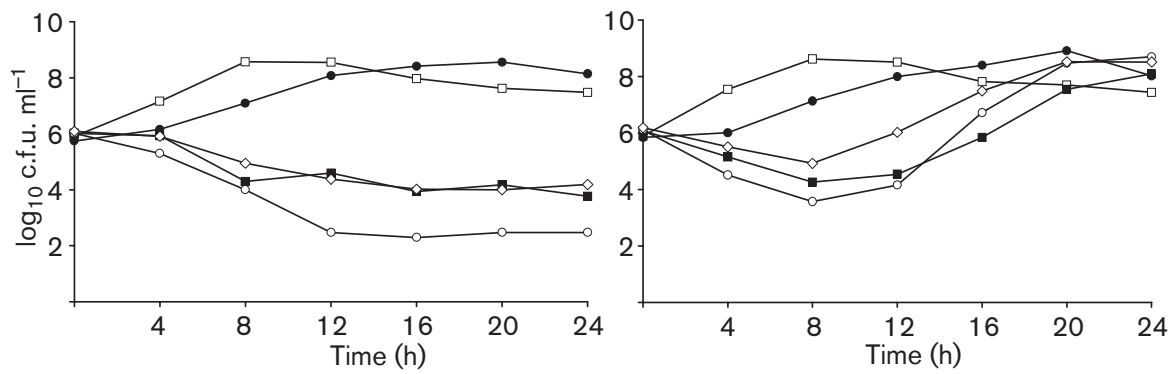

Fig. 1. Growth of the four strains tested following exposure to $0.5 \times$ MICs of the described antibiotics. Strains: VPI 10463 (a), 2932 (b), 47 (c) and 314 (d).

Table 4. Toxin levels in supernatant and sonicated cell pellet

Results are shown for strain VPI 10463 only. Toxin A was measured by ELISA and is given as $A_{450}$ values; toxin B was measured using a cytotoxicity assay and the results are given as titres. Positive results for either assay are shown in bold.

\begin{tabular}{|c|c|c|c|c|c|c|c|c|}
\hline \multirow[t]{2}{*}{ Antibiotic } & \multirow[t]{2}{*}{ Toxin } & \multicolumn{7}{|c|}{ Time (h) } \\
\hline & & $\mathbf{0}$ & 4 & 8 & 12 & 16 & 20 & 24 \\
\hline \multirow[t]{4}{*}{ Control } & Toxin A/supernatant & 0 & 0 & 0 & 0.003 & 0.035 & 0.157 & 1.085 \\
\hline & Toxin A/pellet & 0 & 0 & 0 & 0.003 & 1.392 & 3.0 & 3.0 \\
\hline & Toxin B/supernatant & 0 & 0 & 0 & 0 & 27 & 81 & 243 \\
\hline & Toxin B/pellet & 0 & 0 & 0 & 9 & 729 & 6561 & 6561 \\
\hline \multirow[t]{4}{*}{ VAN } & Toxin A/supernatant & 0.005 & 0.321 & 0.596 & 0.567 & 0.564 & 0.650 & 0.560 \\
\hline & Toxin A/pellet & 0.018 & 0.125 & 1.470 & 3.0 & 3.0 & 3.0 & 3.0 \\
\hline & Toxin B/supernatant & 0 & 81 & 243 & 243 & 243 & 243 & 243 \\
\hline & Toxin B/pellet & 3 & 81 & 243 & 729 & 729 & 729 & 729 \\
\hline \multirow[t]{4}{*}{ MTR } & Toxin A/supernatant & 0.007 & 0.057 & 0.350 & 1.154 & 3.0 & 3.0 & 3.0 \\
\hline & Toxin A/pellet & 0.038 & 0.456 & 3.0 & 3.0 & 3.0 & 3.0 & 3.0 \\
\hline & Toxin B/supernatant & 0 & 81 & 243 & 729 & 6561 & 6561 & 6561 \\
\hline & Toxin B/pellet & 27 & 243 & 2187 & 6561 & 6561 & 6561 & 6561 \\
\hline \multirow[t]{4}{*}{ LZD } & Toxin A/supernatant & 0.009 & 0.003 & 0.005 & 0.029 & 0.199 & 3 & 3 \\
\hline & Toxin A/pellet & 0.057 & 0.052 & 1.652 & 3 & 3 & 3 & 3 \\
\hline & Toxin B/supernatant & 0 & 0 & 3 & 27 & 81 & 2187 & 6561 \\
\hline & Toxin B/pellet & 0 & 27 & 243 & 2187 & 2187 & 6561 & 6561 \\
\hline \multirow[t]{4}{*}{ CLI } & Toxin A/supernatant & 0.023 & 0.018 & 0.022 & 0.040 & 0.066 & 0.156 & 1.983 \\
\hline & Toxin A/pellet & 0.047 & 0.037 & 0.054 & 0.441 & 2.264 & 2.096 & 2.181 \\
\hline & Toxin B/supernatant & 0 & 0 & 0 & 3 & 27 & 81 & 2187 \\
\hline & Toxin B/pellet & 3 & 3 & 9 & 243 & 2187 & 6561 & 6561 \\
\hline
\end{tabular}




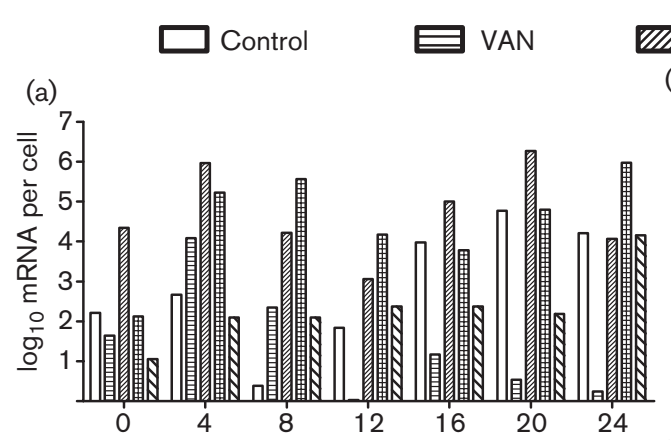

(c)

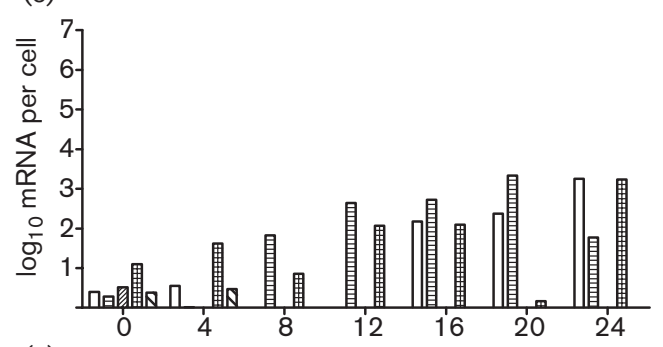

(e)

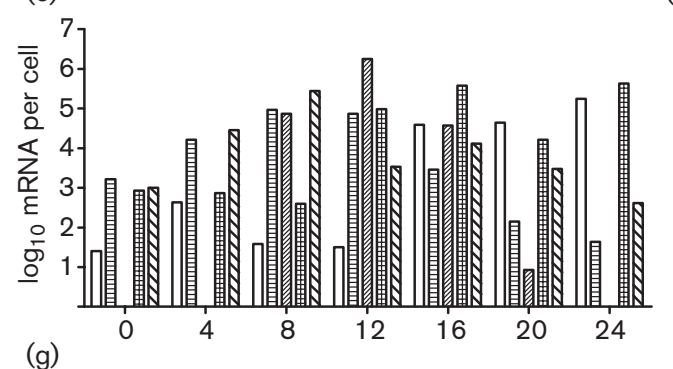

(g)

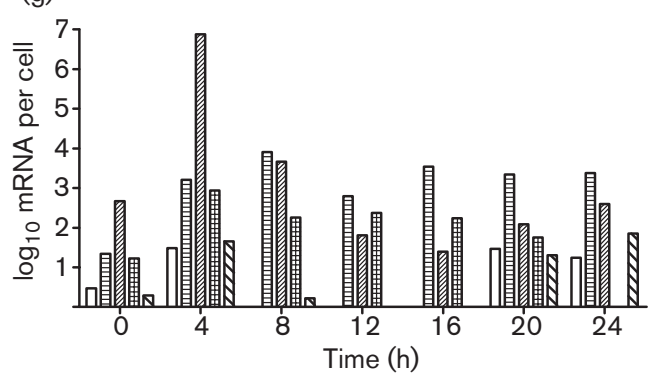

(b)

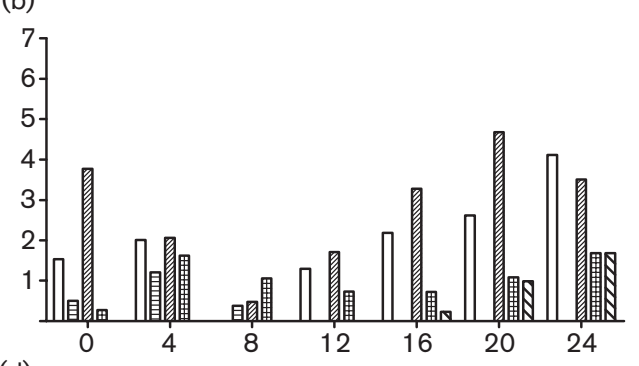

(d)

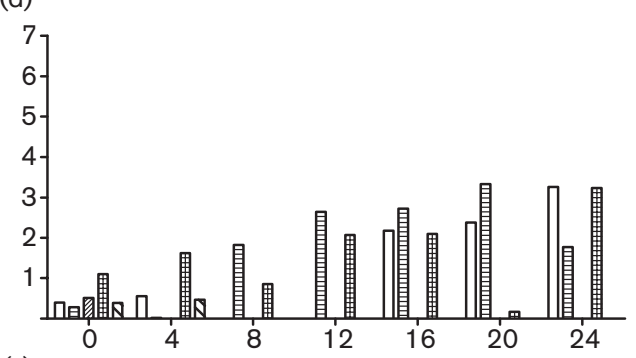

(f)

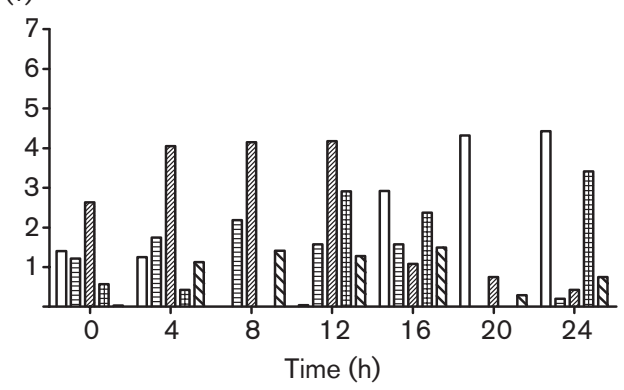

Fig. 2. Number of mRNA copies per bacterial cell of the four strains during 24 h of growth. (a) Strain VPI 10463 tcd $A$; (b) strain VPI $10463 t c d B$; (c) strain $47 t c d A$; (d) strain $47 t c d B$; (e) strain $314 t c d A$; (f) strain $314 t c d B$; (g) strain $2932 t c d B$.

It seems that many antibiotics at low concentrations have the ability to influence gene transcription in a way that is distinct from their inhibitory effect (Goh et al., 2002; Yim et al., 2006). An example of the unexpected effects of antibiotics was found by Rothstein et al. (2005). They showed that $\beta$-lactam antibiotics can stimulate the glutamate transporter GLT1 in cell culture and in animal models (Rothstein et al., 2005).

Further studies of the interactions of sub-MIC concentrations of antibiotics with bacteria and the host could establish effects as described in this study as pharmacological parameters. Pharmacodynamics are important to determine optimal dosing schedules of antibiotics. The relevance of sub-MIC effects may be enhanced when it comes to resistant strains. Here, not only is the MIC higher than in susceptible strains, but the sub-MIC range is also extended. It is possible that a therapeutically applied supraMIC instantly becomes a sub-MIC in a patient with resistant strains. In this case, it seems possible that the antibiotic does not cause a reduction in $C$. difficile levels, but an induction of virulence factors. Although there is only one report on resistance against MTR and VAN, which was not confirmed with further studies (Pelaez et al., 2002), the possibility of resistance occurring in the future cannot be excluded. 
The present study showed that subinhibitory concentrations of various antibiotics modulated transcription of the $t c d A$ and $t c d B$ genes encoding the $C$. difficile toxins $A$ and $B$. The main findings were that VAN, MTR and LZD strongly induced $t c d A$ and $t c d B$ transcription and toxin production in the exponential phase of bacterial growth. This study also indicated that, under subinhibitory concentrations of antibiotics, the increase and earlier release of toxins is a specific process and cannot be explained simply by stress phenomena resulting from destabilization of the bacterial cell.

It is difficult to interpret the effects of antibiotics at subMICs with reference to their clinical use. Observations from in vitro experiments cannot be transferred to in vivo conditions. However, it can be assumed that exposure to antibiotics above the MIC will always be followed by subMICs. At this stage of research, advice on clinical therapy based on the results of this study cannot be given. The gut model used by Baines et al. (2005) could be a promising approach for a closer in vivo-like investigation of antimicrobial agents and toxin production in C. difficile.

Recent reports of new epidemic strains of ribotype 027 indicate that there is a correlation between disease severity and different toxin strain variants (Warny et al., 2005). LZD was found to be effective against $C$. difficile (Ackermann et al., 2003), and VAN and MTR are firstline therapy drugs in the treatment of $C$. difficile infection. The results presented here show that, in vitro, these antibiotics can induce the production of toxins $\mathrm{A}$ and $\mathrm{B}$ in C. difficile.

To our knowledge, this is the first report that describes a mRNA quantification method based on LightCycler technology in $C$. difficile. As most CDADs are multifactorial, further studies, including animal models and clinical trials, are necessary to elucidate more clearly the effects of antibiotics on the pathogenesis of severe $C$. difficile infection. As a major nosocomial pathogen, $C$. difficile continues to be the subject of intense research, providing a greater understanding of the complex pathogenesis by which CDAD develops. In this regard, sensitive gene-based hybridization techniques, such as that described in this report, are valuable tools that may help gain further insights into the pathogenesis and physiology of C. difficile.

\section{REFERENCES}

Ackermann, G., Adler, D. \& Rodloff, A. C. (2003). In vitro activity of linezolid against Clostridium difficile. J Antimicrob Chemother 51, 743745.

Baines, S. D., Freeman, J. \& Wilcox, M. H. (2005). Effects of piperacillin/tazobactam on Clostridium difficile growth and toxin production in a human gut model. J Antimicrob Chemother 55, 974982.

Barc, M. C., Depitre, C., Corthier, G., Collignon, A., Su, W. J. \& Bourlioux, P. (1992). Effects of antibiotics and other drugs on toxin production in Clostridium difficile in vitro and in vivo. Antimicrob Agents Chemother 36, 1332-1335.

Bartlett, J. G., Moon, N., Chang, T. W., Taylor, N. \& Onderdonk, A. B. (1978). Role of Clostridium difficile in antibiotic-associated pseudomembranous colitis. Gastroenterology 75, 778-782.

Davies, J., Spiegelman, G. B. \& Yim, G. (2006). The world of subinhibitory antibiotic concentrations. Curr Opin Microbiol 9, 445453.

Dineen, S. S., Villapakkam, A. C., Nordman, J. T. \& Sonenshein, A. L. (2007). Repression of Clostridium difficile toxin gene expression by CodY. Mol Microbiol 66, 206-219.

Dodson, A. P. \& Borriello, S. P. (1996). Clostridium difficile infection of the gut. J Clin Pathol 49, 529-532.

Dove, C. H., Wang, S. Z., Price, S. B., Phelps, C. J., Lyerly, D. M., Wilkins, T. D. \& Johnson, J. L. (1990). Molecular characterization of the Clostridium difficile toxin A gene. Infect Immun 58, 480-488.

Drummond, L. J., Smith, D. G. \& Poxton, I. R. (2003). Effects of subMIC concentrations of antibiotics on growth of and toxin production by Clostridium difficile. J Med Microbiol 52, 1033-1038.

Dupuy, B. \& Sonenshein, A. L. (1998). Regulated transcription of Clostridium difficile toxin genes. Mol Microbiol 27, 107-120.

Dupuy, B., Mani, N., Katayama, S. \& Sonenshein, A. L. (2005). Transcription activation of a UV-inducible Clostridium perfringens bacteriocin gene by a novel sigma factor. Mol Microbiol 55, 11961206.

Farrell, R. J. \& LaMont, J. T. (2000). Pathogenesis and clinical manifestations of Clostridium difficile diarrhea and colitis. Curr Top Microbiol Immunol 250, 109-125.

George, W. L., Sutter, V. L., Citron, D. \& Finegold, S. M. (1979). Selective and differential medium for isolation of Clostridium difficile. J Clin Microbiol 9, 214-219.

Goh, E. B., Yim, G., Tsui, W., McClure, J., Surette, M. G. \& Davies, J. (2002). Transcriptional modulation of bacterial gene expression by subinhibitory concentrations of antibiotics. Proc Natl Acad Sci U S A 99, 17025-17030.

Hall, I. C. \& O'Toole, E. (1935). Intestinal flora in newborn infants with description of a new pathogenic anaerobe. Am J Dis Child 49, 390-402.

Hennequin, C., Janoir, C., Barc, M. C., Collignon, A. \& Karjalainen, T. (2003). Identification and characterization of a fibronectin-binding protein from Clostridium difficile. Microbiology 149, 2779-2787.

Honda, T., Hernadez, I., Katoh, T. \& Miwatani, T. (1983). Stimulation of enterotoxin production of Clostridium difficile antibiotics. Lancet 321, 655 .

Hundsberger, T., Braun, V., Weidmann, M., Leukel, P., Sauerborn, M. \& von Eichel-Streiber, C. (1997). Transcription analysis of the genes tcdA-E of the pathogenicity locus of Clostridium difficile. Eur J Biochem 244, 735-742.

Ikeda, D., Karasawa, T., Yamakawa, K., Tanaka, R., Namiki, M. \& Nakamura, S. (1998). Effect of isoleucine on toxin production by Clostridium difficile in a defined medium. Zentralbl Bakteriol 287, 375-386.

Jones, E. M., Kirkpatrick, B. L., Feeney, R., Reeves, D. S. \& MacGowan, A. P. (1997). Hospital-acquired Clostridium difficile diarrhoea. Lancet 349, 1176-1177.

Karlsson, S., Burman, L. G. \& Akerlund, T. (1999). Suppression of toxin production in Clostridium difficile VPI 10463 by amino acids. Microbiology 145, 1683-1693.

Karlsson, S., Dupuy, B., Mukherjee, K., Norin, E., Burman, L. G. \& Akerlund, T. (2003). Expression of Clostridium difficile toxins A and B 
and their sigma factor $\mathrm{TcdD}$ is controlled by temperature. Infect Immun 71, 1784-1793.

Kelly, C. P., Pothoulakis, C. \& LaMont, J. T. (1994). Clostridium difficile colitis. N Engl J Med 330, 257-262.

Larson, H. E., Price, A. B., Honour, P. \& Borriello, S. P. (1978). Clostridium difficile and the aetiology of pseudomembranous colitis. Lancet 311, 1063-1066.

Levner, M., Wiener, F. P. \& Rubin, B. A. (1977). Induction of Escherichia coli and Vibrio cholerae enterotoxins by an inhibitor of protein synthesis. Infect Immun 15, 132-137.

Nakamura, S., Mikawa, M., Tanabe, N., Yamakawa, K. \& Nishida, S. (1982). Effect of clindamycin on cytotoxin production by Clostridium difficile. Microbiol Immunol 26, 985-992.

Odenholt, I., Walder, M. \& Wullt, M. (2007). Pharmacodynamic studies of vancomycin, metronidazole and fusidic acid against Clostridium difficile. Chemotherapy 53, 267-274.

Ohlsen, K., Ziebuhr, W., Koller, K. P., Hell, W., Wichelhaus, T. A. \& Hacker, J. (1998). Effects of subinhibitory concentrations of antibiotics on alpha-toxin ( $h l a)$ gene expression of methicillinsensitive and methicillin-resistant Staphylococcus aureus isolates. Antimicrob Agents Chemother 42, 2817-2823.

Onderdonk, A. B., Lowe, B. R. \& Bartlett, J. G. (1979). Effect of environmental stress on Clostridium difficile toxin levels during continuous cultivation. Appl Environ Microbiol 38, 637-641.
Pelaez, T., Alcala, L., Alonso, R., Rodriguez-Creixems, M., GarciaLechuz, J. M. \& Bouza, E. (2002). Reassessment of Clostridium difficile susceptibility to metronidazole and vancomycin. Antimicrob Agents Chemother 46, 1647-1650.

Pepin, J., Saheb, N., Coulombe, M. A., Alary, M. E., Corriveau, M. P., Authier, S., Leblanc, M., Rivard, G., Bettez, M. \& other authors (2005). Emergence of fluoroquinolones as the predominant risk factor for Clostridium difficile-associated diarrhea: a cohort study during an epidemic in Quebec. Clin Infect Dis 41, 1254-1260.

Rothstein, J. D., Patel, S., Regan, M. R., Haenggeli, C., Huang, Y. H., Bergles, D. E., Jin, L., Dykes Hoberg, M., Vidensky, S. \& other authors (2005). $\beta$-Lactam antibiotics offer neuroprotection by increasing glutamate transporter expression. Nature 433, 73-77.

Spizek, J. \& Rezanka, T. (2004). Lincomycin, clindamycin and their applications. Appl Microbiol Biotechnol 64, 455-464.

Warny, M., Pepin, J., Fang, A., Killgore, G., Thompson, A., Brazier, J., Frost, E. \& McDonald, L. C. (2005). Toxin production by an emerging strain of Clostridium difficile associated with outbreaks of severe disease in North America and Europe. Lancet 366, 1079-1084.

Yim, G., Wang, H. H. \& Davies, J. (2006). The truth about antibiotics. Int J Med Microbiol 296, 163-170.

Yoh, M., Yamamoto, K., Honda, T., Takeda, Y. \& Miwatani, T. (1983). Effects of lincomycin and tetracycline on production and properties of enterotoxins of enterotoxigenic Escherichia coli. Infect Immun 42, $778-782$. 